\title{
Cystatin C: A Better Predictor of Kidney Function in Diabetic Patients
}

\author{
TS Shima1, A K hatun2, F Y easmin3 \\ S Ferdousi 4 , K Kirtania5, N Sultana6 \\ ${ }^{1}$ Dept of Biochemistry, Shahabuddin Medical College; 2D ept of Biochemistry, Dhaka D ental College, \\ ${ }^{3}$ Dept of Clinical Biochemistry, D haka Dental College; ${ }^{4}$ Dept of Biochemistry, NIKDU; \\ 5D ept of Biochemistry, J ahurul Islam M edical College; \\ 6 Dept of Biochemistry, D haka Medical College
}

ABSTRACT

Serum cystatin $\mathrm{C}$ is a new promising marker of renal function. The aim of this study was to analyze serum cystatin $C$ as a better predictor of renal function in diabetic nephropathy. In 60 diagnosed diabetic patients, serum cystatin $C$ and serum creatinine were assessed. Glomerular filtration rate was estimated based on the cystatin $C$ concentration according to Cockcroft- Gault formula and based on serum creatinine concentration according to $L$ arsson formula. DTPA-GFR (Diethylenetriamene pentaacetate Renogram) was done as reference standard. The cross tabulation of DTPA-GFR was done with eGFR- creatinine and eGFRcystatin C. The calculated sensitivity, specificity and accuracy of eGFR-creatinine were $85 \%, 87.2 \%$ and $85 \%$ respectively. The eGFR- cystatin C showed higher sensitivity, specificity and accuracy than eGFR- creatinine in studied diabetic subjects. The cystatin C showed more significant correlation, $r=0.78, p<0.001$ than serum creatinine, $r=0.59$, $p<0.001$ with DTPA-GFR in diabetic patients. This study demonstrates that serum cystatin $\mathrm{C}$ may be used for early prediction for renal function impairment in diabetic kidney disease.

Key Words: Cystatin C, DTPA-GFR, eGFR-creatinine, eGFR-Cystatin C A breviation: eGFR - Estimated Glomerular Filtration Rate

\section{Introduction}

Diabetes mellitus is a metabolic disease characterized by defects in insulin secretion, insulin action or both. The number of people with diabetes is increasing due to population growth, aging, urbanization and the increasing prevalence of obesity and physical inactivity. A pproximately $40 \%$ of patients with type I diabetes and $5-15 \%$ of patients with type II diabetes eventually develop End Stage Renal Disease (ESRD)1. Even a diabetic patient is under treatment, there is a risk of development of nephropathy. The risk is related to the length of time the person has diabetes. There is good evidence that early treatment delays or prevents the onset of diabetic nephropathy. Therefore prevention of diabetic renal disease or at least the postponement of or slowing down the disease process, has emerged as a key issue? However our ability to assess renal function is poor in early diabetic nephropathy, when active management is important3. Glomerular filtration rate is the best overall index of renal function in health and disease. While insulin, 51cr- labeled EDTA, 99mT c- labeled DTPA plasma clearance are considered as the gold standard methods for estimating glomerular filtration rate.

Serum creatinine and creatinine clearance are the most widely used indices for the routine noninvasive estimation of GFR. Creatinine is usually measured by the Jaffe reaction, based on a complex formation between alkaline picrate and creatinine 4 . The serum creatinine concentration may be significantly influenced by 
several extra renal factors. Serum creatinine is considered relatively specific but not very sensitive because serum creatinine remains in the normal range until $50 \%$ of renal function is lost. This is creatinine blind area. Here GFR range is between $40-90 \mathrm{ml} / \mathrm{min} / 1.73 \mathrm{~m}^{2}$. It is the area where mild to moderate decrease in GFR occurs. An early reduction of GFR does not show with serum creatinine in the creatinine blind area. Serum creatinine will give false negative results in creatinine blind area. $V$ arious creatinine based equation have been developed in an attempt to improve the estimation of GFR from serum creatinine. Among these, the Cockcroft- Gault $(C \& G)$ formula and the modification of diet in renal disease (MDRD) formula are widely used. But those are also limited by lack of validation in the full range of GFR to which they are applied4. So a more precise and accurate marker of GFR as an assessment of renal function would be clinically useful.

Cystatin $C$ has been proposed as a good marker of GFR, particularly in patients with mild to moderate renal impairment 5 . It is a nonglycosylated protein belonging to the cystene super family (inhibitors of cystene proteinases). Cystatin $C$ is produced by all nucleated cells and its rate of production is constant. The production is not altered by inflammatory conditions, is not related to lean muscle mass. Because of its low molecular mass (approx. $13000 \mathrm{kpa}$ ) and its positive charge at physiological $\mathrm{PH}$, cystatin $\mathrm{C}$ easily crosses the glomerular filter, after filtration, the proximal tubular cells reabsorb and catabolize virtually all of the filtered cystatin $C$. It was demonstrated that the renal clearance of cystatin $C$ is closely related to GFR, measured as 51-CR-EDTA clearance. Cystatin $C$ does not have a blind area will therefore show a positive reaction of GFR. One of most significant advantages of cystatin $C$ in comparison with traditional markers of renal impairment is that very small reductions in GFR cause significant increase in cystatin $C$ serum levels?.
From pathophysiological point of view earlier the diagnosis better will be the prevention of progress in diabetic nephropathy. So it is essential to detect the early impairment of renal function in diabetic patient. This study is aimed to assess the performance of serum cystatin $C$ as an early marker of GFR in diabetic nephropathy and to take preventive measures.

\section{Materials And Methods}

A cross-sectional study was conducted in the outpatient department of BIRDEM hospital during the period from July 2008 to J une 2009. A total 60 diagnosed patients of both sexes were selected as cases. Ethical clearance for the study was taken from the Ethical Review Committee of DMC and BIRDEM hospital. Exclusion criteria were history of diabetes mellitus for more than 5 years, rheumatic diseases, malignancy, cardiac diseases and drug history of taking steroids or cyclosporine.

After maintenance of all aseptic precautions, 5 $\mathrm{ml}$ of venous blood was drawn from each subject and transferred to a clean, dry test tube to clot. Then the sample was centrifuged and serum was collected in an eppendorf tube and preserved at $-20{ }^{\circ} \mathrm{C}$. Then serum creatinine and serum cystatin $C$ were measured. Estimated GFR were calculated from Cockcroft-Gault formula and $L$ arson formula respectively. DTPA-GFR was done as reference standard. Finally comparison was done between two diagnostic procedures, eGFR-creatinine and eGFR-cystatin $C$ with reference standard (DTPA-GFR).

Serum cystatin $C$ concentration and serum creatinine concentration were estimated by particle-enhanced Immunonephelometry using the BN Systems6 and Jaffey reaction method7 respectively. Finally DTPA renogram was done (Peace Harbor Hospital Imaging Services, 2005).

Statistical Analysis: All data were recorded and expressed as mean \pm standard deviation (SD). Statistical analysis was performed by using SPSS software package program. Sensitivity, specificity and accuracy were measured for 
TS Shima, A K hatun, $F$ Y easmin et al

eGFR- Cystatin C and eGFR-creatine. The ROC (Receiver Operator Characteristics) curve was constructed. The Pearson correlation analyses were performed for eGFR-Cystatin C and eGFRCreatinine with DTPA-GFR. A greement test was done between two diagnostic procedures.

\section{Results}

Table 1 shows the descriptive statistics of the outcome variables. Mean ( $\pm S D$ ) Serum Creatinine of the subjects was $0.83( \pm 0.25)$ $\mathrm{mg} / \mathrm{dl}$, Mean $( \pm \mathrm{SD})$ Serum Cystatiin $C$ was $0.94( \pm 0.09) \mathrm{mg} / \mathrm{L}$, M ean $( \pm \mathrm{SD})$ eGFRcreatinine was $109.10( \pm 15.51) \mathrm{ml} / \mathrm{min} / \mathrm{m} 2$, Mean $( \pm S D)$ eGFR-cystatinC was $96.75( \pm 10.91) \mathrm{ml} / \mathrm{min} / \mathrm{m} 2$.

Table I: Descriptive statistics of the outcome variables

\begin{tabular}{lllll} 
Variables Number & M inimum & M aximum & M ean & Std.Deviation \\
\hline Serum Creatinine 60 & .48 & 1.70 & 0.83 & 0.25 \\
Serum Cystain C 60 & .68 & 1.14 & 0.94 & 0.09 \\
eGFR -C reatinine 60 & 69.38 & 154.21 & 109.10 & 15.51 \\
eGFR -CystatinC 60 & 67.71 & 129.25 & 96.75 & 10.91
\end{tabular}

Table 2 shows cross tabulation of serum Creatinine versus serum Cystatin C. Out of 16 subjects, who had abnormal serum creatinine, 3 had normal serum Cystatine $C$. O ut of 44 subjects, who had normal serum Creatinine 3 had abnormal serum Cystatin C. The agreement test done between two diagnostic tests, serum cystatine $\mathrm{C}$ and serum creatinine. The agreement test showed $\mathrm{K}=0.74$ that means good agreement. The cut off value of serum creatinine is $1.2 \mathrm{mg} / \mathrm{dl}$ and serum Cystatin $C$ is $0.98 \mathrm{mg} / \mathrm{L}$.

Table II: Serum Creatinine versus Serum Cystatin C cross tabulation

\begin{tabular}{lrcr}
\hline \multirow{2}{*}{$\begin{array}{l}\text { Serum Creatinine } \\
\text { A bnormal }\end{array}$} & \multicolumn{2}{c}{ Serum Cystatin C } \\
\hline N ormal & Total \\
A bnormal 13 & 3 & 16 & \\
N ormal 3 & 41 & 44 & \\
Total 16 & 44 & 60 \\
\hline
\end{tabular}

Table III: eGFR - Creatinine versus eGFR-DTPA cross tabulation

\begin{tabular}{|c|c|c|c|}
\hline \multirow{2}{*}{$\begin{array}{l}\text { Serum Creatinine } \\
\text { A bnormal }\end{array}$} & \multicolumn{3}{|c|}{ Serum Cystatin C } \\
\hline & & Normal & Total \\
\hline A bnormal 10 & 6 & & \\
\hline Normal 3 & 41 & & \\
\hline Total 13 & 47 & & \\
\hline
\end{tabular}

Sensitivity $=85 \%$; Specificity $=87.2 \%$; A ccuracy $=85 \%$

Table 3 shows cross tabulation of eGFRCreatinine versus eGFR DTPA. Out of 16 subjects, who had abnormal eGFR-creatinine, 6 had normal eGFR DTPA .Out of 44 subjects, who had normal eGFR-Creatinine 3 had abnormal eGFR DTPA. Sensitivity, Specificity and Accuracy of eGFR-Creatinine was $85 \%, 87.2 \%$ and $85 \%$ respectively. The cut off value of normal GFR is $90 \mathrm{ml} / \mathrm{min} / \mathrm{m}^{2}$.

Table IV: eGFR- Cystatine C versus eGFR-DTPA cross tabulation

\begin{tabular}{lccc}
\hline $\begin{array}{l}\text { Serum Creatinine C } \\
\text { A bnormal }\end{array}$ & \multicolumn{2}{c}{ Serum Cystatin C } \\
Normal & Total \\
\hline A bnormal 12 & 4 & 16 & \\
Normal 1 & 43 & 44 \\
Total 13 & 47 & 60 \\
\hline
\end{tabular}

Sensitivity $=92.3 \% \%$ ； Specificity $=91.5 \%$; A ccuracy $=98.33 \%$

Table IV shows cross tabulation of eGFRCystatine $C$ versus eGFR-DTPA. Out of 16 subjects, who had abnormal eGFR-Cystatine C, 4 had normal eGFR-DTPA .Out of 44 subjects, who had normal eGFR-Cystatin C 1 had abnormal eGFR DTPA. Sensitivity, Specificity and A ccuracy of eGFR-Cystatine C was $92.3 \%$, $91.5 \%$ and $98.33 \%$ respectively. The cut off value of normal GFR is $90 \mathrm{ml} / \mathrm{min} / \mathrm{m}^{2}$. 
Cystatin C: A Better Predictor of Kidney Function

Table V: Correlation test between eGFR-Creatinine and eGFR-DTPA

\begin{tabular}{lrcr} 
Serum Creatinine C & \multicolumn{2}{c}{ Serum Cystatin C } \\
A bnormal & & Normal & Total \\
\hline A bnormal 10 & 6 & 16 \\
N ormal 3 & 41 & 44 \\
Total 13 & 47 & 60 \\
\hline
\end{tabular}

Pearson's $r=0.59 ; p<0.001$

Table $\mathrm{V}$ shows correlation between eGFRCreatinine and eGFR DTPA. Statistical analysis with correlation test showed significant result. Here $r=0.59, p<0.001$. The cut off value of normal GFR is $90 \mathrm{ml} / \mathrm{min} / \mathrm{m}^{2}$.

Table VI: Correlation test between eGFR- Cystatine $C$ and eGFR-DTPA

\begin{tabular}{lrcrl}
\hline \multirow{2}{*}{$\begin{array}{l}\text { Serum Creatinine C } \\
\text { A bnormal }\end{array}$} & \multicolumn{3}{c}{ Serum Cystatin C } \\
Normal & Total & \\
\hline A bnormal 12 & 4 & 16 & \\
N ormal 1 & 43 & 44 & \\
Total & 13 & 47 & 60 \\
\hline
\end{tabular}

Pearson's $r=0.78 ; p<0.001$

Table VI shows correlation between eGFRCystatine $C$ and eGFR DTPA. Statistical analysis with correlation test showed significant result. Here $r=0.78, p<0.001$. The cut off value of normal GFR is $90 \mathrm{ml} / \mathrm{min} / \mathrm{m} 2$

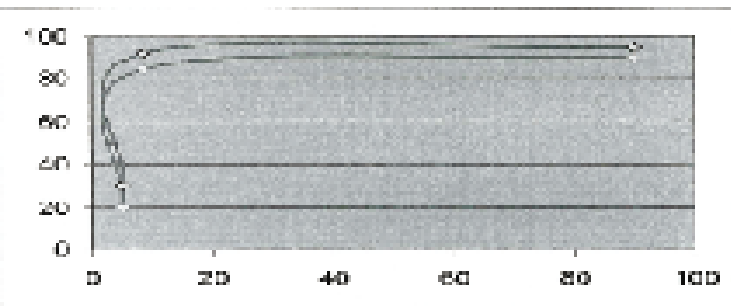

Figure I: The ROC (Receiver Operator Characteristic) Curve plots to assess the diagnostic efficiency of serum Cystatin $C \&$ serum Creatinine estimated GFR. The area under curve (AUC) of eGFR-Cystatin $C$ is 0.88 and eGFRCreatinine is 0.85 . So, the accuracy of the tests are good.

\section{Discussion}

Diabetes has become the most common single cause of end stage renal disease (ESRD). In the U.S., diabetic nephropathy accounts for about $40 \%$ of new cases of ESRD. A ssessment and follow up of early renal dysfunction is important in diabetic nephropathy. Cystatin C concentration has been proposed as an endogenous marker of GFR superior to creatinine8.

In this cross sectional study, serum Cystatin C, serum creatinine \& serum glucose has been measured. The age of the study subjects ranged from 32-60 years; mean \pm SD of age were 40.67 $( \pm 6.23)$ years. The mean duration of $D M \pm S D$ of the patients were $3.76( \pm 0.78)$ years. The mean $\pm S D$ of the serum creatinine \pm SD of the patients were $0.94( \pm 0.09) \mathrm{mg} / \mathrm{L}$. The mean eGFR-Cystatin C \pm SD were 109.10 ( \pm 15.51$)$ $\mathrm{ml} / \mathrm{min} / \mathrm{m}^{2}$. The meaneGFR-Cystatin $\mathrm{C} \pm \mathrm{SD}$ of the patients were $96.75( \pm 10.91) \mathrm{ml} / \mathrm{min} / \mathrm{m}^{2}$.

The cross tabulation of DTPA-GFR was done with eGFR-creatinine and eGFR-Cystatin C. The calculated sensitivity, specificity and accuracy of eGFR-creatinine were $85 \%, 87.2 \%$ and $85 \%$ respectively. The sensitivity, specificity and accuracy of eGFR-CystatinC were $92.3 \%, 91.5 \%$ and $98.33 \%$ respectively. The eGFR Cystatin showed higher sensitivity, higher specificity and higher accuracy than eGFR creatinine in studied diabetic subjects. This finding is consistent with other studied2,9. The agreement test done between serum cystatin $\mathrm{C}$ and serum creatinine. The test showed $\mathrm{K}=0.74$ which indicates good agreement. Moreover, Pearson's correlation test was done. Cystatin C showed more significant correlation $r=0.78$, $p<0.001$ than serum creatinine, $r=0.59 . p<0.001$ with DTPA-gfr in diabetic patients. This findings are consistent with other studies10,11. The Receiver Operator Characteristics (ROC) curves were generated by plotting the sensitivity versus specificity. Accuracy is measured by the area under the ROC curve. The area under curve $(A \cup C)$ of eGFR- cystatin $C$ is 0.88 and the AOC of eGFRcreatinine is 0.88 . So the accuracy of the eGFRCystatin $C$ is superior to eGFR-creatinine. Thus serum Cystatin $C$ may be a better predictor of renal function in diabetic patients than serum creatinine? 
In may be concluded that stimation of GFR using an appropriate method is a reliable measure of the kidney function and impairment in diabetic nephropathy. The inadequacy of the traditional markers in detecting early changes in GFR particularly monitoring the course of advanced diabetic nepfropathy calls for alternative non-invasive methods in clinical nephrology. Cystatin $C$ seems to be an alternative and more accurate serum marker than serum creatinine for early detection of nephropathy in diabetic patients for which early treatment is important. Thus, serum Cystatin C might be a superior marker of GFR evaluation compared to creatinine and might be added to routine renal tests.

\section{R eferences}

1. Evans TC, Cappel P. Diabetic Nephropathy. Clinical Diabetes 2000; 18:7-21.

2. M ussap $M$, Vestra $M D$, Fioretto $P$, Sallar A, Varagnolo M , Nosadini R, Plebani M. Cystatin C is a more sensitive marker than creatinine for the estimation of GFR in type 2 diabetic patients. Kidney International 2002; 61:1453-61.

3. Tan GD, Lewis AV, James TJ, Altmann P,Taylor RP, L evy JC.Clinical U sefulness of Cystatin C for the Estimation of Glomerular Filtration Rate in Type 1 Diabetes. Diabetes Care 2002; 25: 2004-9.

4. Hojs R, Bevc S, Ekart R, Gorenjak M,Puklavec L. Serum Cystatin $C$ as an endogenous marker of renal function in patients with mild to moderate impairment of kidney function. Nephrol Dial Transplantat 2006; 21:1855-62.
5. Uzun $\mathrm{H}$, Ozmen KM, Taman R, Aydin $\mathrm{S}$, Kalender $B$, Uslu E, et al. Serum Cystatin C level as a potentially good marker for impaired kidney function. Clin Biochem 2005; 38:792-8.

6. Finney $\mathrm{H}$, Newman DJ, Gruber W, Merle P, Price $C P$. Initial Evaluation of Cystatin $C$ measurement by particle Enhanced immunonephelometry on the behring nephelometer system. Clini Chemi 1997; 43:1016-22.

7. M urray RL, Kaplan A. Creatinine.Clin Chem 1984; 1:1261-66.

8. Premaratne $E, M$ aclsaac RJ, Finch S,Panagiotopoulos $S$, Ekinci $E$, Jerums $G$. Serial M easurement of Cystatin C A re More Accurate Than CreatinineBased $M$ ethods in D etecting Decling Renal Function in Type 1 Diabetes. Diabetes Care 2008; 31: 971-3.

9. Buysschaert $M$, J oudi I,Wallemacq $P, H$ ermans M P.Comparative performance of serum Cystatin C versus serumcreatinine in diabetic subject. Diabetes and M etabolism 2003; 29: 377-83.

10. El-A groudy $A E$, Sabry AA, Ghanem HA, EL-Baz A, Fakhry A, Gad HM et al. Serum Cystatin C: A good marker for evaluation of glomerular filtration rate in hepatorenal syndrome. EJ General Medicine 2004; 1: 29-35.

11. Xia LH, Bing XG, AnXT. Serum Cystatin $C$ assay for the detection of early renal impairment in diabetic patients. JC Lab A nal 2004; 18: 31-35. 